\title{
Restricted Expression of G86R Cu/Zn Superoxide Dismutase in Astrocytes Results in Astrocytosis But Does Not Cause Motoneuron Degeneration
}

\author{
Yun H. Gong, ${ }^{1}$ Alexander S. Parsadanian, ${ }^{2}$ Albina Andreeva, ${ }^{1}$ William D. Snider, ${ }^{3}$ and Jeffrey L. Elliott ${ }^{1}$ \\ ${ }^{1}$ Department of Neurology, University of Texas, Southwestern Medical Center, Dallas, Texas 75235, ${ }^{2}$ Department of \\ Neurology, Washington University School of Medicine, St. Louis, Missouri 63110, and 3University of North Carolina \\ Neuroscience Center, School of Medicine, University of North Carolina, Chapel Hill, North Carolina 27599
}

Evidence garnered from both human autopsy studies and genetic animal models has suggested a potential role for astrocytes in the pathogenesis of amyotrophic lateral sclerosis (ALS). Currently, mutations in the gene encoding $\mathrm{Cu} / \mathrm{Zn}$ superoxide dismutase (SOD1) represent the only known cause of motoneuron loss in the disease, producing $21 \mathrm{q}$ linked familial ALS (FALS). To determine whether astrocytic dysfunction has a primary role in familial ALS, we have generated multiple lines of transgenic mice expressing G86R mutant SOD1 restricted to astrocytes. In GFAP-m SOD1 mice, astrocytes exhibit significant hypertrophy and increased GFAP reactivity as the animals mature. However, GFAP-mutant SOD1 transgenic mice develop

Amyotrophic lateral sclerosis (ALS) is characterized by the progressive loss of motoneurons, leading to profound weakness and death of affected individuals. Because it is motoneurons that invariably die in ALS, most attention has focused on these cells as the primary site where pathophysiological injury is initiated. However, evidence garnered from human autopsy studies and genetic animal models has suggested a potential role for astrocytes in the pathogenesis of ALS. Abnormalities in astrocytic function particularly related to glutamate transport have been well documented in ALS patients. Astrocytes from the brains of ALS patients manifest selective decreases in expression of fulllength and functional EAAT-2 protein, which serves as the principle glutamate transporter in the CNS (Rothstein et al., 1994, 1995, 1996). Recent investigations have shown that aberrant processing of EAAT-2 mRNA transcripts occurs in ALS astrocytes and yields alternatively spliced forms of the protein that act as dominant negative inhibitors of normal EAAT-2 expression function (Lin et al., 1998). Such decreases in functional astroglial EAAT-2 expression in vivo potentially explain the significant reduction in glutamate transport function observed in synaptosomes from ALS brains and, as well, the overall elevation in CSF glutamate levels observed in ALS patients (Rothstein et al., 1992). Together these findings have led to the formulation of a hypothesis concerning ALS pathogenesis in which astrocyte dys-

Received Aug. 19, 1999; revised Oct. 20, 1999; accepted Oct. 22, 1999.

This work was supported by grants from the National Institute of Neurological Diseases and Stroke (NS01853) to J.L.E. and Muscular Dystrophy Association to J.L.E. and W.D.S. We thank Laura Lee Deane for expert technical assistance and Dr. Larry Honig for valuable discussions.

Correspondence should be addressed to Dr. Jeffrey L. Elliott, Department of Neurology, University of Texas, Southwestern Medical Center, 5323 Harry Hines Boulevard, Dallas, Texas 75235. E-mail: jellio@mednet.swmed.edu.

Copyright (C) 2000 Society for Neuroscience $0270-6474 / 00 / 200660-06 \$ 15.00 / 0$ normally and do not experience spontaneous motor deficits with increasing age. Histological examination of spinal cord in aged GFAP-mSOD1 mice reveals normal motoneuron and microglial morphology. These results indicate that $21 \mathrm{q}$ linked FALS is not a primary disorder of astrocytes, and that expression of mutant SOD1 restricted to astrocytes is not sufficient to cause motoneuron degeneration in vivo. Expression of mutant SOD1 in other cell types, most likely neurons, is critical for the initiation of disease.

Key words: amyotrophic lateral sclerosis; glutamate; mouse; transgenic; glia; gliosis

function is critical (Bai and Lipton, 1998). However, partly because the pathogenesis of sporadic ALS is unknown, no model system exists to test whether observed alterations in astrocytes contribute significantly to the disease process.

Although the etiology of sporadic ALS is unknown, mutations in the gene encoding $\mathrm{Cu} / \mathrm{Zn}$ superoxide dismutase (SOD1) have been found to cause one form of familial ALS (FALS) (Rosen et al., 1993). The process by which mutant (m) SOD1 leads to motoneuron degeneration remains unclear, but studies involving the use of transgenic animals clearly point to a toxic gain of function model for the abnormal protein. Mice with targeted deletions of both SOD1 alleles do not develop spontaneous motoneuron loss (Reaume et al., 1996). In contrast, transgenic mice overexpressing mSOD1 develop spontaneous motoneuron degeneration and represent an excellent animal model of the disease (Gurney et al., 1994; Ripps et al., 1995; Wong et al., 1995; Tu et al., 1996).

Astrocytic alterations occur in mSOD1 transgenic mice. Pathological examination of transgenic mice expressing a G85R mSOD1 demonstrates abnormal protein inclusions in astrocytes even at early clinically presymptomatic time points when motoneuron pathology is not readily apparent (Bruijn et al., 1997). In addition, these mice also exhibit selective loss of the principal astrocytic glutamate transporter GLT-1 and manifest alterations in glutamate transport function, mirroring those observed in human disease (Bruijn et al., 1997; Canton et al., 1998). However, experiments to date have been unable to delineate whether the astrocyte abnormalities observed in mSOD1 transgenic mice represent primary dysfunction of this cell type or occur secondary to neuronal injury, let alone determine whether these astrocytic changes contribute to disease pathogenesis or represent epiphenomena. 
Conventional lines of mSOD1 mice are problematic for understanding the role of astrocytes in the disease process. Because these lines use the endogenous SOD1 promoter to drive transgene expression, mSOD1 is expressed ubiquitously in all cells including neurons and glia. Consequently, these animals are unsuitable to determine which cell type is critical in initiating the process leading to motoneuron loss. We therefore have generated transgenic mice expressing mSOD1 under the control of an astrocyte-specific promoter and asked whether such mice develop spontaneous motoneuron degeneration and astrocytic pathology.

\section{MATERIALS AND METHODS}

Construct design and generation of GFAP-G86R transgenic mice. A cDNA encoding full-length normal murine SOD1 was obtained using P1 mouse brain RNA, reverse-transcribed with random primers (Superscript reverse transcriptase). An aliquot of this mixture was then used to amplify normal murine SOD1 cDNA. Primers were used (5[prime- ACT AGT ATG GCG ATG AAA GCG GTG-3' and 5'-GGA TCC TGT TTA CTG GGC AAT CCC-3') to amplify the full-length murine SOD1 with Spe1 and BamHI restriction sites on the $5^{\prime}$ and $3^{\prime}$ end, respectively. PCR conditions were $94^{\circ} \mathrm{C}$ for $4 \mathrm{~min}, 94^{\circ} \mathrm{C}$ for $1 \mathrm{~min}, 60^{\circ} \mathrm{C}$ for $1 \mathrm{~min}$, and $72^{\circ} \mathrm{C}$ for $1.5 \mathrm{~min}$ for 35 cycles followed by a $7 \mathrm{~min}$ extension at $72^{\circ} \mathrm{C}$. A band corresponding to a 465 nucleotides was obtained and cloned directly into a PCR II cloning vector (Invitrogen, San Diego, CA). After sequencing to confirm normal SOD1 sequence, this plasmid was digested with SpeI and Bam HI and then cloned into pBluescript II(p-SOD2). This plasmid was then used to generate G86R SOD1. For this amino acid substitution, the base at position 256 must be changed from $\mathrm{G}$ to $\mathrm{C}$. A reverse primer incorporating this change was designed using sequence 250 to 294, which also has Ball site at the $3^{\prime}$ end (5'-CAC ATT GGC CAC ACC GTC CTT TCC AGC AGT CAC ATT GCG CAG GTC-3'). This primer and the original 5' SOD1 primer (listed above) were used to amplify a $295 \mathrm{bp}$ fragment, which was then cloned (p-BAL frag) and sequenced to confirm the appropriate $\mathrm{G}$ to $\mathrm{C}$ change at 256 . After a Spe1and BalI digestion, this altered 295 bp SOD fragment was ligated into PSOD2, which had also undergone SpeI and BalI digestion to then yield a full-length SOD1 with a $\mathrm{G}$ to $\mathrm{C}$ change at 256 (p-BAL-SOD1). This plasmid was confirmed again by sequencing. A $2.3 \mathrm{~kb}$ fragment (Brenner et al., 1994) containing the $5^{\prime}$ flanking DNA sequence derived from the human glial fibrillary acidic protein (GFAP) gene was available in Bluescript SK II with flanking SpeI sites. This GFAP promoter was excised with SpeI and ligated into the SpeI site of p-BAL-SOD to generate p-GFAP-mSOD. An 850 bp SV40 small t-antigen with an intron and polyadenylation sequence was cloned into PGFAP-SOD using EcoRV and SalI sites to generate p-GFAP-mSOD1-SV40, which was then excised with NotI and SalI and used for pronuclear injection (strainB6/CBA). Integration of the transgene into the mouse genome was determined by Southern blotting and PCR on genomic DNA extracted from mouse tails.

Southern blot and PCR analysis. Ten micrograms of genomic DNA isolated from mouse tail were digested with digested with Bam $\mathrm{HI}$ and $K p n I$, separated on a $0.8 \%$ agarose gel, and then transferred to a positive charged nylon membrane (Boehringer Mannheim, Indianapolis, IN) via overnight capillary transfer. A dig-dUTP 450 bp probe generated by PCR (PCR-dig kit; Boehringer Mannheim), corresponding to full-length SOD1 cDNA, was used for hybridization in DIG Easy Hyb solution (Boehringer Mannheim) at $42^{\circ} \mathrm{C}$. Hybridization of probe and DNA fragment were visualized the using the DIG-Luminescent Kit (Boehringer Mannheim) following the instructions of the manufacturer. Films were be scanned and compared semiquantitatively between the differing transgenic lines using NIH Image software (version 1.61). PCR analysis (30 cycles: $94^{\circ} \mathrm{C}$ for $1 \mathrm{~min}, 64^{\circ} \mathrm{C}$ for $45 \mathrm{sec}$, and $72^{\circ} \mathrm{C}$ for $1 \mathrm{~min} 20 \mathrm{sec}$ ) was performed for routine identification of mice carrying the transgene using primers encompassing the $5^{\prime}$ end of SOD1 and extending $150 \mathrm{bp}$ into the SV40 sequence.

In situ hybridization. In situ hybridization was performed following methods previously described (Deckwerth et al., 1996; Parsadanian et al., 1998). Animals were deeply anesthetized with sodium pentobarbital and then decapitated. Spinal cord and brain were rapidly dissected out, frozen on dry ice, and $12 \mu \mathrm{M}$ sections were cut on a Zeiss micom cryostat. Plasmid (p-SV40-1) containing the fragments encoding the 850 bp SV40 small $t$-antigen were linearized with appropriate restriction enzymes for subsequent sense and antisense in vitro transcription The antisense probe recognizes only transgene mRNA. cRNA probes were transcribed in vitro using the appropriate RNA polymerase in the presence of $50 \mu \mathrm{Ci}$ ${ }^{33} \mathrm{P}[\mathrm{UTP}]$ (NEN). Hybridization occurred overnight at $55^{\circ} \mathrm{C}$ in the presence of $1 \times 10^{6} \mathrm{cpm}{ }^{33} \mathrm{P}[\mathrm{UTP}$ ] labeled riboprobe diluted in a hybridization mixture. The following day slides were rinsed in $4 \times \mathrm{SSC}$, at $37^{\circ} \mathrm{C}$, followed by a $30 \mathrm{~min}$ wash in RNase $\mathrm{A}(20 \mathrm{mg} / \mathrm{ml})$ at $45^{\circ} \mathrm{C}$. Slides were then rinsed at $37^{\circ} \mathrm{C}$ in $2 \times \mathrm{SSC}, 0.5 \times \mathrm{SSC}$, and $0.1 \times \mathrm{SSC}$. Slides were then exposed to Biomax film (Eastman Kodak, Rochester, NY) for 3-4 d to generate autoradiographs. Slides were dipped in Kodak NTB-2 emulsion and stored in light-tight boxes for 2 weeks, developed with Kodak developer and fixer, and counterstained with hematoxylin and eosin.

Western blotting. Animals were overdosed with sodium pentobarbital ( $250 \mathrm{mg} / \mathrm{kg}$, i.p.). Spinal cords were dissected, homogenized (in mM: 20 Tris-HCl, pH 7.5, 2 DTT, 1 EDTA, and 1 EGTA, with leupeptin 0.1 $\mathrm{mg} / \mathrm{ml}$ ), then centrifuged at $13,000 \times g$ with pelleted debris discarded. Protein concentration was measured using the BCA protein assay (Pierce, Rockford, IL). Five micrograms of protein from each sample was loaded on a $14 \%$ Tris-glycine gel (Novex). A range of known concentrations of bovine SOD 1 (Sigma, St. Louis, MO) were loaded. Gel was gently rinsed with transfer buffer (Tris base $12 \mathrm{~mm}$, glycine $96 \mathrm{~mm}$, and $20 \%$ methanol) and placed against a polyvinylidene difluoride membrane. Transfer was performed at $25 \mathrm{~V}, 100 \mathrm{~mA}$ for $2 \mathrm{hr}$. Membranes were washed in PBS followed by incubation in blocking solution [0.2\% I-block (Tropix), PBS, and $0.1 \%$ Tween 20] overnight at room temperature. Membrane was incubated with primary antibody, a polyclonal rabbit anti-bovine SOD1 (Chemicon, Temecula, CA) antibody, at 1:4000 dilution in blocking buffer for 1-2 hr. After washing, membrane was incubated with a secondary anti-rabbit antibody-alkaline phosphatase conjugate (Tropix) (1:5000 in blocking buffer) as well as with an Avidix-AP streptavidin-alkaline phosphatase conjugate $(1: 20,000)$ for 1 hr. After washing, the membrane underwent a 5 min incubation with CSPD chemoluminescent alkaline phosphatase substrate (Tropix). After exposure to Kodak X-omat film, films were scanned and then imported into NIH Image for quantitation of band density.

Stride test. This test was performed with modifications from Gurney et al. (1994). Animals were trained to walk across a $1 \mathrm{~m}$ flat board. These animals then had their hindpaws dipped with a nontoxic ink and were allowed to walk across the $1 \mathrm{~m}$ board that had white construction paper over the top for recording footprints. Stride lengths were measured in millimeters. Statistics on data were be performed using Student's $t$ test. All procedures performed on mice were approved by an animal research committee and conform to National Institutes of Health guidelines.

Immunochemistry and histology. After overdose with pentobarbital, animals were perfused with $4 \%$ paraformaldehyde and had spinal cords and brains removed. For routine histology, tissue was embedded in plastic, sectioned $(1 \mu \mathrm{m})$, and stained with toluidine blue. For immunohistochemistry, paraffin-embedded sections $(4 \mu \mathrm{m})$ were incubated with a rabbit polyclonal GFAP antibody (Dako, Glostrup, Denmark) (1:200 dilution) and visualized using an immunoperoxidase reaction (the one kit, Sternberger Monoclonals). For studies of morphology, four GFAPmSOD1 and three wild-type littermates were used for each time period studied (4 and 12 months of age). Multiple sections from GFAP-mSOD1 and wild-type sibling lumbar spinal cords were processed and stained simultaneously. Photomicrographs were taken, scanned, and then imported into NIH Image version 1.61, where the area of GFAP-positive astrocytes (in pixels) was obtained. At least 250 astrocytes from GFAPmSOD1 and wild-type littermates of 4 and 12 months of age were used per age group. Measurements were performed by a single investigator who was unaware of the animal genotype. To assess microglia, sections were washed in TBS followed by overnight incubation with a tomato (Lycopersicon esculentum) lectin (Sigma) conjugated to fluorescein (1:70 dilution). G93A conventional mSOD1 mice were obtained from The Jackson Laboratory (Bar Harbor, ME).

\section{RESULTS}

\section{Construct design and line analysis of GFAP-(m)SOD1 transgenic mice}

To generate transgenic mice expressing G86R mSOD1 restricted to astrocytes, we designed a construct that uses a $2.3 \mathrm{~kb}$ flanking sequence 5' to the human GFAP gene (Brenner et al., 1994). This promoter region has been shown to drive high levels of astrocytespecific expression in transgenic mice beginning at early postnatal periods and extending into adulthood (Brenner et al., 1994; 

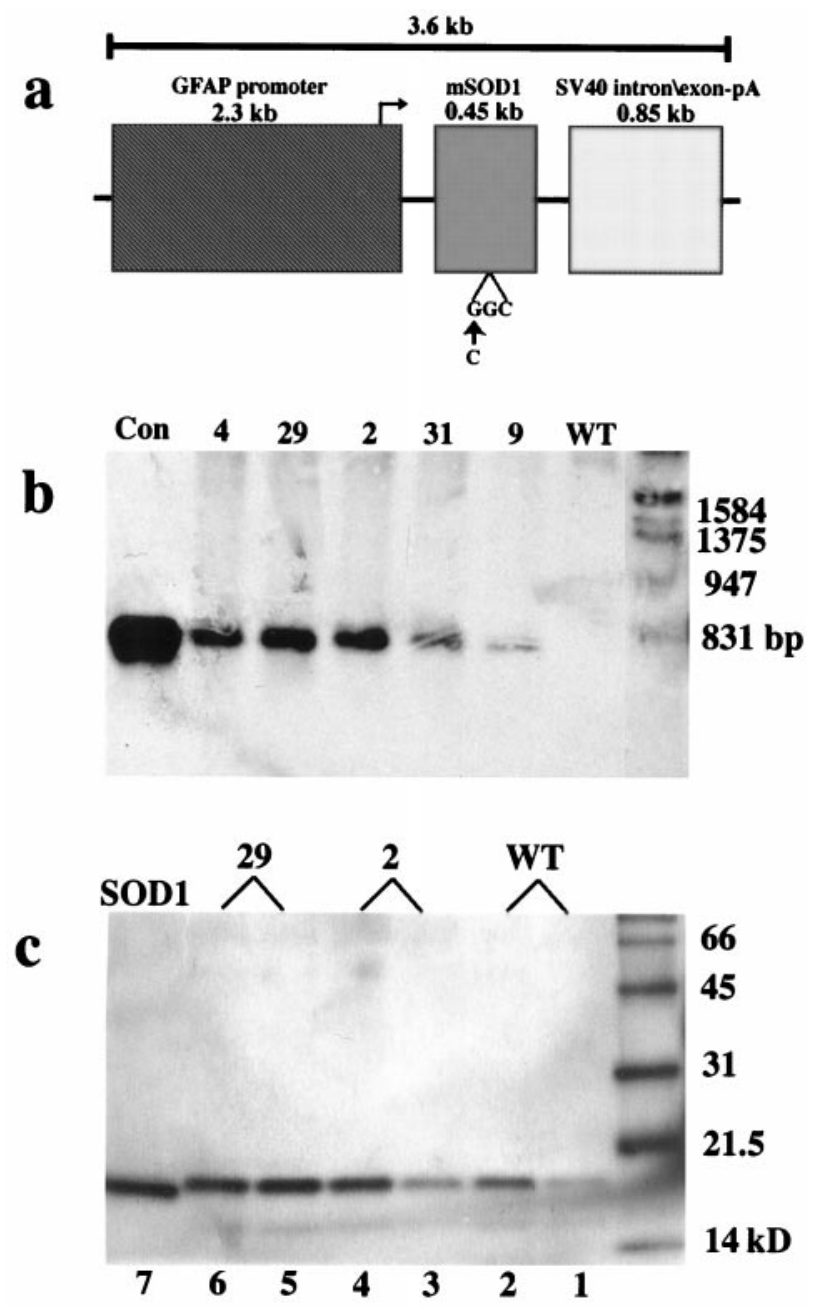

Figure 1. a, Schematic representation of construct used in generation of GFAP-mSOD1 mice. The $\mathrm{C}$ for $\mathrm{G}$ substitution in the first base at codon 86 causes a glycine to arginine change. $b$, Southern blot analysis of GFAP-mSOD1 transgenic lines. Bam HI and KpnI digestion of DNA yields a 729 bp fragment in transgenic mice. Con, p-GFAP-mSOD1-SV40; $W T$, wild-type. $c$, Western blot analysis of SOD1 in spinal cords from adult GFAP-mSOD1 and wild-type mice using rabbit anti-bovine SOD1. Lanes 1, 2, Wild-type (WT) mouse; $2.5 \mu \mathrm{g}$ and $5 \mu \mathrm{g}$ of total protein loaded, respectively. Lanes 3, 4, Line $5512-2 ; 2.5 \mu \mathrm{g}$ and $5 \mu \mathrm{g}$ of total protein loaded. Lanes 5, 6, Line 5512-29; $5 \mu \mathrm{g}$ and $2.5 \mu \mathrm{g}$ of total protein loaded. Lane 7, Bovine SOD1 control; $0.02 \mu \mathrm{g}$ of protein loaded.

Raeber et al., 1997). This promoter fragment is also capable of driving transgene upregulation in the setting of an injury, which would typically result in increased GFAP protein synthesis, such as occurs in conventional mutant SOD1 transgenic mice. We selected the murine G86R SOD1 mutation (G85R in humans) because earlier experiments had shown that expression of this altered protein under the control of the endogenous SOD1 promoter is capable of producing motoneuron disease in vivo with both neuronal and astrocytic dysfunction (Ripps et al., 1995; Bruijn et al., 1997). Figure $1 a$ demonstrates the overall construct design used for pronuclear injection and the generation of GFAPSOD1 transgenic mice.

After injection of the transgene construct, six founder mice (5512-2, 5512-4, 5512-9, 5512-19, 5512-29, and 5512-31) were identified by initial PCR screening. Relative transgene copy number was determined by Southern blot analysis after digestion of
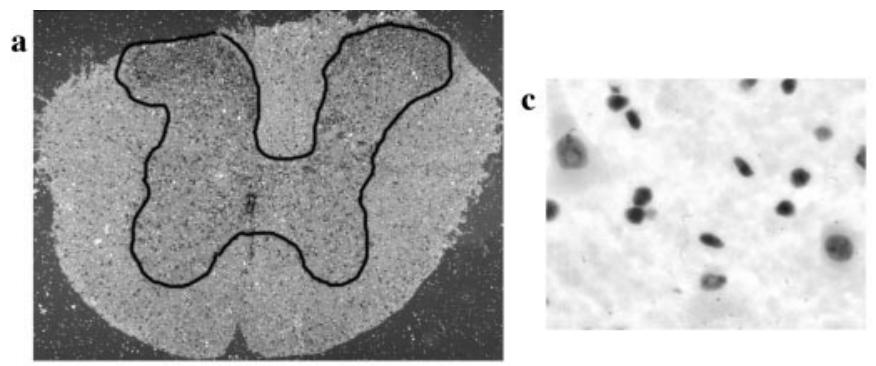

b
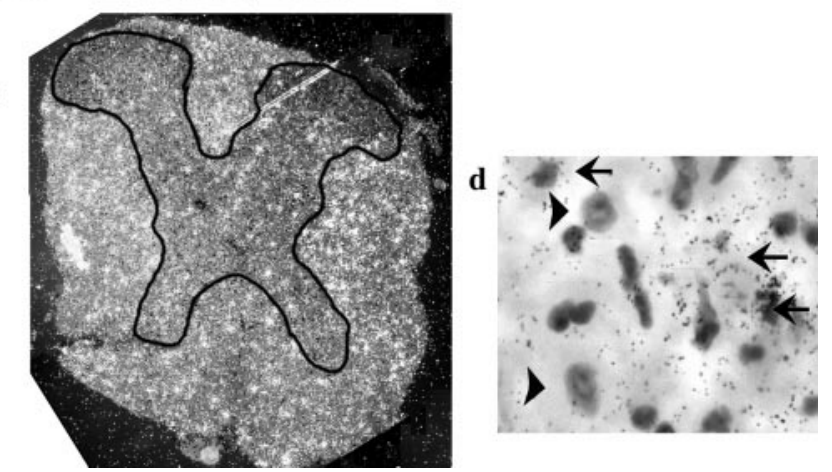

Figure 2. Expression of mSOD1 transgene is restricted to non-neuronal cells in the spinal cord. $a, b$, Transverse sections of spinal cord from 6-week-old wild-type $(a)$ and line 5512-29 GFAP-mSOD1 (b) mice hybridized with antisense riboprobe for the SV40 sequence, which detects only transgene expression. Dark-field microscopy, Magnification, $40 \times . c$, $d$, Bright-field views of wild-type $(c)$ and GFAP-mSOD1 $(d)$ ventral horn. Arrowheads indicate neuronal cell bodies. Silver grains are observed only over glial cells in GFAP-mSOD1 mice (arrows). Magnification, 400×.

genomic DNA with BamHI and HindIII (Fig. 1b). This digestion yields a 729 bp fragment of the transgene that encompasses the entire SOD1 cDNA and a 250 bp segment of the $3^{\prime}$ end of the GFAP promoter. Relative transgene copy number differed for each line varying from line 5512-9 (1x) to line 5512-29 (10x). Lines 5512-29 and 5512-2 demonstrated the highest number of transgene copies and were used for further analysis of transgene transcription and translation. Line 5512-19 exhibited a rearrangement of the transgene, and although still bred, was not used for further experiments.

To assess whether transgene incorporation resulted in increased protein production, we performed Western blot analysis on spinal cords from lines 5512-29 and 5512-2 (Fig. 1c). Available antibodies against SOD1 were not capable of distinguishing between normal and mutant murine SOD1, so total SOD1 protein levels were assayed. Initial blots performed on tissue from 6-week-old animals revealed significantly increased levels of total SOD1 protein expression in spinal cords from transgenic GFAPmSOD1 transgenic mice as compared to wild-type controls. Correlating with copy number, line 5512-29 demonstrated higher total SOD1 expression than did line 5512-2. Increased total SOD1 expression in spinal cord was also observed in older transgenic GFAP-mSOD1 mice up to 5 months of age (the oldest age examined). We next used in situ hybridization to test whether expression of the mutant SOD1 was in fact restricted to astrocytes (Fig. 2). By generating a riboprobe complimentary to the SV40 t-antigen, we were able to distinguish the cells that were transcribing the transgene. In situ hybridization demonstrated robust transgene synthesis in both white and gray matter portions of spinal cord from line 5512-29. High-power bright-field microscopy revealed that expression of transgene was limited to glial 


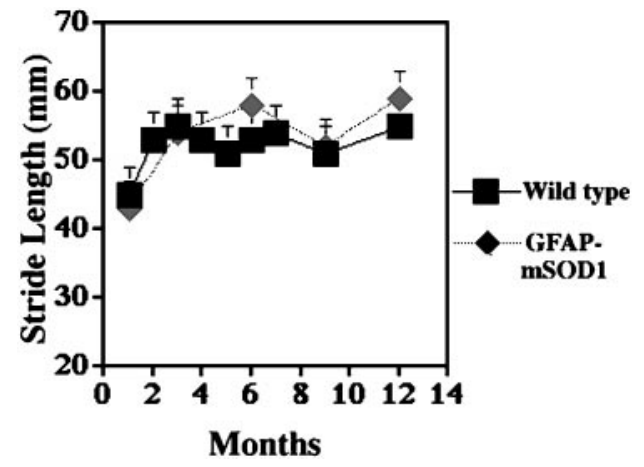

Figure 3. Stride length in GFAP-mSOD1 transgenic female mice from line 5512-29 and wild-type littermates. There is no significant difference in stride length between the two groups. $n=4$ for each group.

cells and not neurons. Similar findings were observed in brainstem sections from 5512-29 mice. GFAP-mSOD1 mice from line 5512-2 also expressed transgene message limited to glial cells in spinal cord and brainstem, but again correlating with total copy number and results from Western blotting, line 5512-2 exhibited overall less robust transgene expression than did 5512-29.

\section{GFAP-SOD1 survival and motor function}

All six GFAP-mSOD1 transgenic founders were bred and followed longitudinally for signs of motor dysfunction as well as for survival analysis. GFAP-mSOD1 mice exhibited normal early development, reproductive capacity, and survival curves comparable to wild-type mice at least until 16 months of age (the oldest age yet attained). Founder 5512-2 did die suddenly at 4 months of age. However, this founder demonstrated no signs of motor dysfunction before death, and its transgenic offspring are alive at 1 year of age. Even up to 16 months of age, GFAP-mSOD1 mice do not display abnormalities in gross motor function or postural reflexes. The stride length test was used to assess motor function quantitatively, in a method that had been used to test motor function in conventional mutant SOD1 mice (Fig. 3). Compared to wild-type littermates, GFAP-mSOD1 mice exhibited an identical pattern of stride length distance beginning at 1 month of age and continuing until past 1 year of age. Thus, at least for the first 16 months of life, GFAP-mSOD1 mice do not appear to develop clinical signs of motor neuron dysfunction.

\section{Neuronal and glial morphology in GFAP-mSOD1 transgenic mice}

We performed histological and immunhistochemical analysis on 1-year-old GFAP-mSOD1 mice from line 5512-29 to determine whether these mice developed any pathological evidence of neuronal or glial dysfunction. Thin plastic sections of spinal cord ventral horn demonstrated normal motoneuron morphology without evidence of cytoplasmic vacuoles (Fig. 4). Imunnohistochemical analysis with antibodies directed against phosphorylated neurofilaments or ubiquitin in GFAP-mSOD1 mouse tissue did not reveal any neuronal inclusions in spinal cord motor neurons that are characteristic of affected neurons in conventional mSOD1 mice (data not shown).

We next asked whether glia manifested any morphological or biochemical abnormalities. Immunostaining spinal cord from GFAP-mSOD1 demonstrated increased GFAP reactivity as compared to wild-type age-matched littermates (Fig. 5). In addition, astrocytic morphology had changed from fine stellate-appearing cells in wild-type animals to a larger and more globular appear-
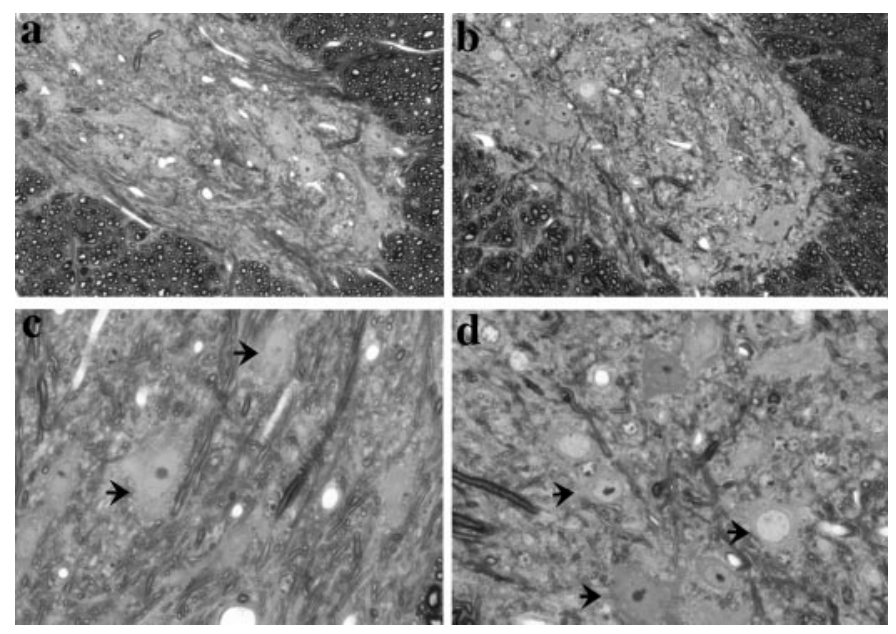

Figure 4. Toluidine-stained plastic sections of the ventral horn from 1-year-old wild-type $(a, c)$ and line 5512-29 GFAP-mSOD1 mice $(b, d)$. Arrows indicate motoneurons. Magnification, $200 \times$ for $a$ and $b ; 600 \times$ for $c$ and $d$.

ance in GFAP-mSOD1 mice. GFAP-immunoreactive spinal cord astrocytes were significantly larger in GFAP-mSOD1 mice compared to age-matched wild-type controls [mean area (pixels) \pm SEM: WT, $147 \pm$ 8; GFAP-mSOD1, $225 \pm 8$; $p<0.001]$. However, changes in both GFAP reactivity and astrocytic hypertrophy in GFAP-mSOD1 mice were not as extensive as those observed in endstage conventional mutant SOD1 transgenic mice with a mean area of $392 \pm 29$ pixels for astrocytes. Interestingly, changes in astrocytic morphology were not observed in the ventral horn of younger GFAP-mSOD1 mice. At 4 months of age, there was no difference in size between spinal cord astrocytes in wild-type $(138 \pm 5$ pixels $)$ and GFAP-mSOD1 mice $(143 \pm 9$ pixels). This finding indicates that the astrocytosis in GFAPmSOD1 mice is not present at younger ages but develops as the animals mature.

To assess changes in microglia we used a lectin (L. esculentum) that binds poly $N$-acetyl lactosamine residues in both activated and nonactivated microglia (Acarin et al., 1994). Both wild-type and GFAP-mSOD1 mice exhibit rare microglia in spinal cord in contrast with the markedly increased number of microglia present in conventional mutant SOD1 mouse spinal cord (data not shown). These results indicate that if mutant SOD1 expression is astrocyte specific, than pathological changes appear restricted to this cell type and do not promote subsequent neuronal dysfunction or microglial proliferation.

\section{DISCUSSION}

Although previous studies have described abnormalities in astrocytes in both autopsied human ALS tissue as well as in transgenic mouse models of FALS, they have not adequately addressed the issue of whether primary astrocytic dysfunction is capable of causing motoneuron degeneration in ALS. Mutant SOD1 expression in vivo provides a model system to test whether astrocytic changes induced by mSOD1 are critical in the pathogenesis of ALS. Here we demonstrate that mutant SOD1 expression limited to astrocytes results in significant changes to this cell type in transgenic mice but is not sufficient to cause motoneuron death or motor dysfunction in vivo. Although it is possible that with even higher levels of mSOD1 production in astrocytes, we may have observed motoneuron loss, we feel that this occurrence is unlikely 
A

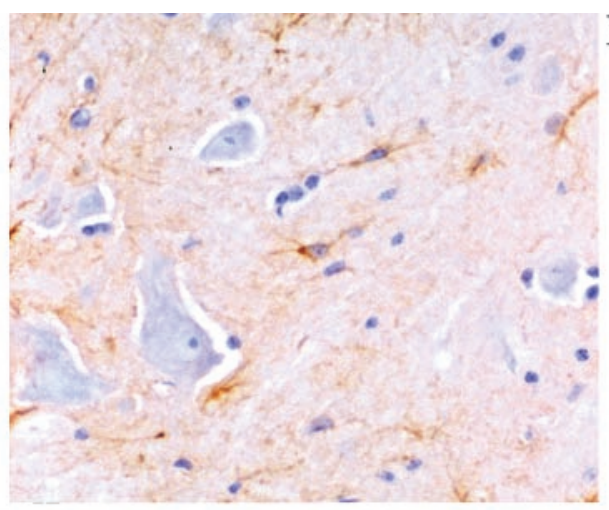

B

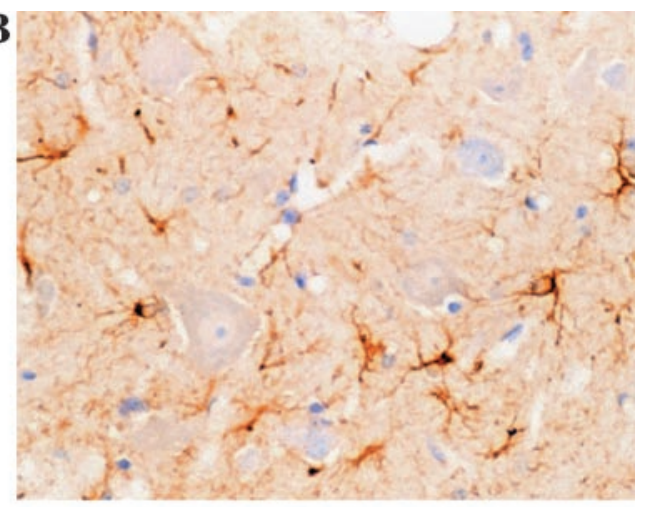

Figure 5. Astrocyte morphology in the ventral horns of 1-year-old wild-type $(A)$, 1-year-old GFAP-mSOD1 $(B)$, and 8-month-old (endstage) G93A SOD1 (C) mice identified by GFAP immunoreactivity. Magnification, $400 \times . D$, Area of ventral horn GFAP-reactive cells from 1-year-old WT and 5512-29 mice as well as endstage (8 month) G93A SOD1 mice. ${ }^{*} p<0.0001$ versus wild-type.
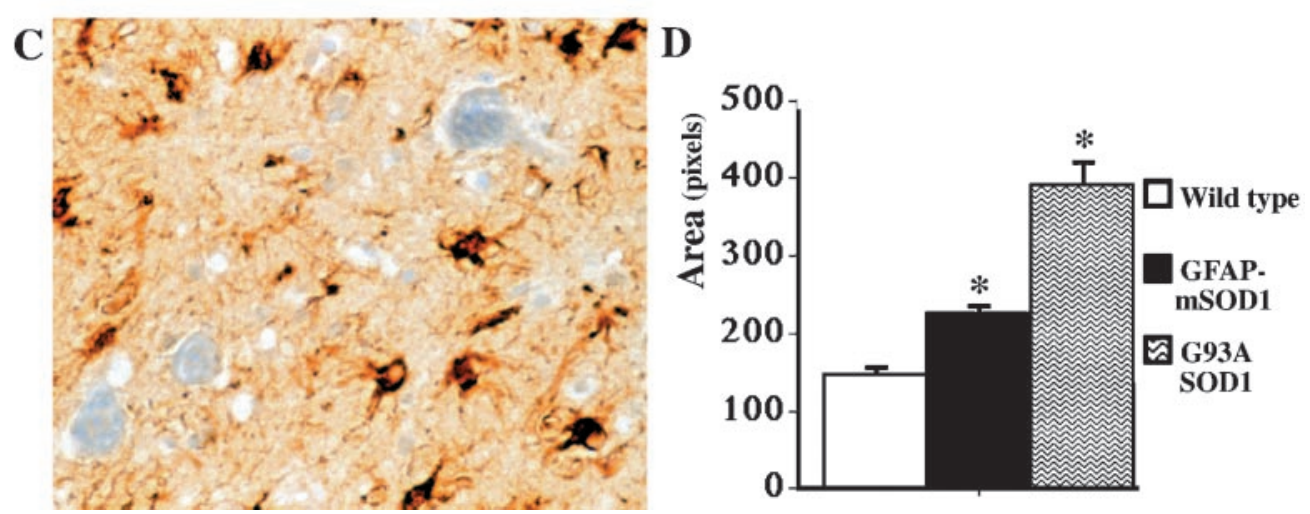

for a number of reasons. First, in conventional mSOD1 transgenic mice, expression of even small amounts of G85R SOD1, representing a fraction of total SOD1 protein produced, is sufficient to cause disease with a time course resulting in death by $\sim 12-14$ months of age (Bruijn et al., 1997). In addition, our in situ hybridization experiments demonstrate that robust transgene transcription in our highest expressing lines of GFAP-mSOD1 mice is widely distributed, occurring not only in glial cells surrounding motoneurons in the ventral horn but also in glia throughout the spinal cord and into white matter tracts. Third, the morphological changes we have observed in GFAP-mSOD1 astrocytes also would offer support of transgene expression at levels capable of altering basic astrocytic properties.

Recently, Trotti et al. (1999) have demonstrated that mSOD1 selectively inactivates the GLT-1 transporter in vitro when both proteins are expressed in Xenopus oocytes and propose that this finding accounts for the toxic properties of mSOD1 leading to motoneuron degeneration. Their experiments and conclusion again imply a principal and critical role for astrocytes in initiation of the disease process. However, our results indicate that $21 \mathrm{q}$ linked FALS is not a primary disease of astrocytes as might be predicted by the glutamate hypothesis, but that expression of mutant SOD1 in another cell type is critical for manifestations of disease. It is likely, although not proven, that neuronal expression of mutant SOD1 is necessary for the disease process and that mutant SOD1 would likely exert its toxic effects directly on motoneurons. Although precise mechanisms of mutant SOD1 toxicity within neurons are unclear, several possibilities including enhanced generation of hydroxyl radicals or increased peroxynitrite formation by the mutant enzyme have been suggested by a number of investigations (Beal et al., 1997; Crow et al., 1997; Ferrante et al., 1997; Bogdanov et al., 1998; Pedersen et al., 1998).
Our results do not exclude the possibility that astrocytes may contribute to progression of FALS after the disease process has been initiated in another cell type. Neurons appear capable of regulating expression of astrocytic proteins possibly via the secretion of diffusable factors as has been demonstrated for glutamate transporter subtypes (Swanson et al., 1997). Primary neuronal dysfunction could trigger inappropriate and harmful astrocytic responses that potentiate neuronal injury or allow its propagation, including release of cytokines or alterations in glutamate transporter expression (Campbell et al., 1993; Chavany et al., 1998).

Although GFAP-mSOD1 mice do not develop motor dysfunction or motoneuron pathology, astrocytes in these animals do undergo changes, including hypertrophy and increased GFAP expression. Because such changes occur in GFAP-mSOD1 mice in whom motoneuron pathology does not occur, this indicates that mSOD1 expression in astrocytes alone is sufficient to cause at least some degree of astrocytosis that is not reactive but primary. The fact that the astrocytosis in GFAP-mSOD1 develops as the mice mature and is not present in younger adult mice suggests that there is a gradual accumulation of potentially noxious factors within astrocytes leading to injury but not degeneration.

It is interesting to note that pronounced alterations in astrocytic morphology have been observed in conventional mutant SOD1 transgenic mice that develop weakness. Remarkably, these changes can be observed in astrocytes located not only in close proximity to motor neuron populations (i.e., ventral horn) but also in astrocytes at a distance from motor pools such as in the dorsal horn or rostral pons. One possible explanation for this phenomenon is that mutant SOD1 exerts its toxic effects on many differing populations of neurons extending beyond motor neuron pools and that astrocytes throughout the CNS then undergo 
changes secondary to this diff use neuronal injury (Dal Canto and Gurney, 1994; Kliveny et al., 1999). However, our experiment would suggest that mSOD1 expression directly within astrocytes is capable of altering astroglial morphology. Together, these results suggest that the astrocytosis in conventional mSOD1 mice is derived from a combination of both secondary astrocytic reaction to neuronal dysfunction as well as primary direct astrocytic dysfunction.

Although this study demonstrates that mutant SOD1-induced disease is not a primary disease of astrocytes, 21q linked FALS is responsible for only $\sim 20 \%$ of familial cases and $<5 \%$ of all ALS cases. It is unclear whether the conclusions reached from studying a transgenic murine model of FALS can be broadened to include the sporadic form of disease, despite common pathological and biochemical features that have been observed both in the animal model and human disease.

\section{REFERENCES}

Acarin L, Vela JM, Gonzalez B, Castellano B (1994) Demonstration of poly- $N$-acetyl lactosamine residues in amoeboid and ramified microglial cells in rat brain by tomato lectin binding. J Histochem Cytochem 42:1033-1041.

Bai G, Lipton SA (1998) Aberrant RNA splicing in sporadic amyotrophic lateral sclerosis. Neuron 20:363-366.

Beal MF, Ferrante RJ, Browne SE, Matthews RT, Kowall NW, Brown Jr RH (1997) Increased 3-nitrotyrosine in both sporadic and familial amyotrophic lateral sclerosis. Ann Neurol 42:646-654.

Bogdanov MB, Ramos L, Xu Z, Beal MF (1998) Elevated hydroxyl radical generation in vivo in an animal model of amyotrophic lateral sclerosis. J Neurochem 71:1321-1324.

Brenner M, Kissebeth WC, Su Y, Besnard F, Messing A (1994) GFAP promoter directs astrocyte- specific expression in transgenic mice. J Neurosci 14:1030-1037.

Bruijn LI, Becher MW, Lee MK, Anderson KL, Jenkins NA, Copeland NG, Sisodia SS, Rothstein JD, Borchelt DR, Price DL, Cleveland DW (1997) ALS-linked SOD1 mutant G85R mediates damage to astrocytes and promotes rapidly progressive disease with SOD1-containing inclusions. Neuron 18:327-338.

Campbell IL, Abraham CR, Masliah E, Kemper P, Inglis JD, Oldsone MB, Mucke L (1993) Neurologic disease induced in transgenic mice by cerebral overexpression of interleukin 6. Proc Natl Acad Sci USA 90:10061-10065.

Canton T, Pratt J, Stutzmann JM, Boireau A (1998) Glutamate uptake is decreased tardively in the spinal cord of FALS mice. NeuroReport 9:775-778

Chavany C, Vicario-Abejon C, Miller G, Jendobi, M (1998) Transgenic mice for interleukin 3 develop motor neuron degeneration associated with auto immune reaction against spinal cord motor neurons. Proc Natl Acad Sci USA 95:11354-11359.

Crow JP, Sampson JB, Zhuang Y, Thompson JA, and Beckman JS (1997) Decreased zinc affinity of amyotrophic lateral sclerosisassociated superoxide dismutase mutants leads to enhanced catalysis of tyrosine nitration by peroxynitrite. J Neurochem 69:1936-1944.

Dal Canto MC, Gurney ME (1994) Development of central nervous system pathology in a murine transgenic model of ALS. Am J Pathol 145:1271-1280.

Deckwerth TL, Elliott JL, Knudson CM, Johnson Jr EM, Snider WD, Korsmeyer SJ (1996) Bax is required for neuronal death after trophic factor deprivation and during development. Neuron 17:401-411.

Ferrante RJ, Shinobu LA, Schulz JB, Mattews RT, Thomas CE, Kowall NW, Gurney ME, Beal MF (1997) Increased 3-nitrotyrosine and oxidative damage in mice with human copper/zinc superoxide dismutase mutation. Ann Neurol 42:326-334.

Gurney ME, Pu H, Chiu AY, Dal Canto MC, Polchow CY, Alexander DD, Caliendo J, Hentati A, Kwon YW, Deng HX, Chen W, Z hai P, Sufit RL, Siddique T (1994) Motor neuron degeneration in mice that express a human $\mathrm{Cu}, \mathrm{Zn}$ dismutase mutation. Science 264:1772-1775.

Kliveny P, Ferrante RJ, Mattews RT, Bogdanov MB, Klein AM, Andrassen OA, Mueller G, Wermer M, Kaddurah-Daouk R, Beal MF (1999) Neuroprotective effects of creatine in a transgenic animal model of amyotrophic lateral sclerosis. Nat Med 5:347-350.

Lin CLG, Bristol LA, Jin L, Dykes-Hoberg M, Crawford T, Clawson L, and Rothstein JD (1998) Aberrant RNA processing in a neurodegenerative disease: the cause for absent EAAT2, a glutamate transporter in amyotrophic lateral sclerosis. Neuron 20:589-602.

Parsadanian ASh, Cheng Y, Keller-Peck C, Holztman DM, Snider WD (1998) Bcl-xL is an antiapoptotic regulator for postnatal CNS neurons. J Neurosci 18:1009-1019.

Pedersen WA, Fu W, Keller JN, Markesberry WR, Appel SA, Smith RG, Kasarkis E, Mattson MP (1998) Protein modification by the lipid peroxidation product 4-hydroxynonenal in the spinal cords of amyotrophic lateral sclerosis patients. Ann Neurol 44:819-824.

Raeber AJ, Race RE, Brandner S, Priola SA, Sailer A, Bessen RA, Mucke L, Manson J, Aguzzi A, Oldstone MB, Weissmann C, Chesebro B (1997) Astrocyte specific expression of hamster prion protein $(\mathrm{PrP})$ renders PrP knockout mice susceptible to hamster scrapie. EMBO J 16:6057-6065.

Reaume AG, Elliott JL, Hoffman EK, Kowal NW, Ferrante RJ, Siwek DF, Wilcox HM, Flood DG, Beal MF, Brown RH, Scott RW, Snider WD (1996) Motor neurons in $\mathrm{Cu} / \mathrm{Zn}$ superoxide dismutase-deficient mice develop normally but exhibit enhanced cell death after axonal injury. Nat Genet 13:43-47.

Ripps ME, Huntley GW, Hof PR, Morrison JH, and Gordon JW (1995) Transgenic mice expressing an altered superoxide dismutase gene provide an animal model of amyotrophic lateral sclerosis. Proc Natl Acad Sci USA 92:689-693.

Rosen DR, Sidduqe T, Patterson D, Figlewicz DA, Sapp P, Hentati A, Donaldson D, Goto J, O'Regan JP, Deng HX, Rahmani Z, Krizus A, McKenna-Yasek, D, Cayabyab A, Gaston SM, Berger R, Tanzi RE, Halperin JJ, Herzfeldt B, Van den Bergh R, Hung WY, Bird T, Deng G, Mulder DW, Smyth C, Laing NG, Soriano E, Perciak-Vance MA, Haines J, Roulou GA, Gusella JS, Horvitz HR, Brown Jr RH (1993) Mutations in $\mathrm{Cu} / \mathrm{Zn}$ superoxide dismutase gene are associated with familial amyotrophic lateral sclerosis. Nature 362:59-62.

Rothstein JD, Martin LJ, Kuncl RW (1992) Decreased glutamate transport by the brain and spinal cord in amyotrophic lateral sclerosis. New Engl J Med 326:1464-1468.

Rothstein JD, Martin L, Levey AI, Dykes-Hoberg M, Jin L, Wu D, Nash N, Kuncl RW (1994) Localization of neuronal and glial glutamate transporters. Neuron 13:713-725.

Rothstein JD, Van Kammen M, Levey AI, Martin LJ, Kuncl RW (1995) Selective loss of glial glutamate transporter GLT-1 in amyotrophic lateral sclerosis. Ann Neurol 38:73-84.

Rothstein JD, Dykes-Hoberg M, Pardo CA, Bristol LA, Jin L, Kuncl RW, Kanai Y, Hediger MA, Wang Y, Schielke JP, Welty DF (1996) Knockout of glutamate transporters reveals a major role of for astroglial transport in excitotoxicity and clearance of glutamate. Neuron 16:675-686.

Swanson RA, Liu J, Miller JW, Rothstein JD, Farrell K, Stein BA, Longuemare MC (1997) Neuronal regulation of glutamate subtype expression in astrocytes. J Neurosci 17:932-940.

Trotti D, Rolfs A, Danbolt NC, Brown Jr RH, Hediger MA (1999) SOD1 mutants linked to amyotrophic lateral sclerosis selectively inactivate a glial glutamate transporter. Nat Neurosci 2:427-433.

Tu PH, Rau P, Robinson KA, Gurney ME, Trojanowski JQ, and Lee V (1996) Transgenic mice carrying a human mutant superoxide dismutase transgene develop neuronal cytoskeletal pathology resembling human amyotrophic lateral sclerosis lesions. Proc Natl Acad Sci USA 93:3155-3160.

Wong PC, Pardo CA, Borchelt DR, Lee MK, Copeland NG, Jenkins NA, Sisodia SS, Cleveland DW, Price DL (1995) An adverse property of a familial ALS-linked SOD1 mutation causes motor neuron disease characterized by vacuolar degeneration of mitochondria. Neuron 14:11051116. 